\title{
The role of a cAMP-dependent pathway in the uterine relaxant action of relaxin in rats
}

\author{
S. J. Hughes ${ }^{*}$, M. Hollingsworth ${ }^{\dagger}$ and K. R. F. Elliott \\ Smooth Muscle Pharmacology and Biochemistry Groups, School of Biological Sciences, \\ University of Manchester, Oxford Road, Manchester M13 9PT, UK
}

\begin{abstract}
The aim of this study was to investigate the role of the adenylyl cyclase pathway, and in particular cyclic AMP-dependent protein kinase A, in the relaxant action of relaxin in the isolated uterus of the nonpregnant rat. The purportedly selective inhibitor of cAMPdependent protein kinase A $N$-[2-(methylamino) ethyl]-5-isoquinolinesulfonamide hydro-

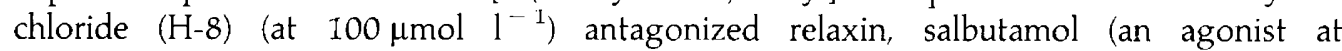
$\beta$-adrenoceptors) and levcromakalim (a $\mathrm{K}^{+}$channel opener) to a similar extent (by factors of 3.1, 1.9 and 2.8, respectively), demonstrating that it is not a selective inhibitor. Relaxin and levcromakalim were less potent and had smaller, maximal, relaxant effects in longitudinal myometrium than in intact uterus cut in the longitudinal plane. By contrast, nifedipine ( $\mathrm{a} \mathrm{Ca}^{2+}$ channel blocker) was equipotent in the two preparations and salbutamol only slightly less potent in the longitudinal myometrium. Relaxin did not alter the cyclic AMP-dependent protein kinase A activity ratio in longitudinal myometrium but did increase the activity ratio by a factor of $2.0 \pm 0.2$ in the intact uterus. Salbutamol, the positive control, increased this activity ratio in both longitudinal myometrium (by $1.9 \pm 0.3$ times) and in the intact uterus (by $3.8 \pm 0.3$ times), whereas the negative control levcromakalim had no effect. Relaxin seems to act as a relaxant of longitudinal myometrium by a cyclic AMP-independent mechanism but possibly interacts with the circular myometrium or endometrium to release a relaxant factor via a cyclic-AMP-dependent mechanism.
\end{abstract}

\section{Introduction}

Relaxin, a polypeptide hormone, is a potent relaxant of uterine smooth muscle (Downing and Hollingsworth, 1993). However, the signal-transduction pathway underlying this effect is uncertain (Hughes and Hollingsworth, 1995, 1996). One hypothesis is that relaxin interacts with plasmalemma receptors in myometrial cells and activates adenylyl cyclase, resulting in the increased formation of CAMP and activation of cAMPdependent protein kinase A (PKA) (Sanborn et al., 1980, 1994).

Evidence supporting the existence of this pathway is the fact that relaxin increases cAMP concentrations in the uterus in vitro (Cheah and Sherwood, 1980; Judson et al., 1980; Sanborn et al., 1980; Hsu et al., 1985; Osa et al., 1991) and after treatment in vivo (Downing et al., 1992). In addition, relaxin increases the total activity of protein kinase A (PKA) in the rat uterus (Kemp and Niall, 1981) and the inhibitory action of relaxin on the oxytocin-induced rise in the intracellular concentration of calcium, $\left[\mathrm{Ca}^{2+}\right]_{\mathrm{i}}$, is blocked by the purportedly selective PKA inhibitor $\mathrm{N}$-[2-(methylamino) ethyl]-5isoquinolinesulfonamide hydrochloride ( $\mathrm{H}-8)$ (Hidaka et al., 1984; Hagiwara et al., 1987) in rat myometrial cells in culture

*Present address: AXESS Ltd, Forest Road, Kew, Richmond, Surrey TW9 3BY, UK.

${ }^{\dagger}$ Correspondence.

Received 8 July 1996.
(Anwer et al., 1990). H-8 also antagonizes relaxin as a uterine relaxant (Sanborn et al., 1994).

There are, however, some results that do not support the role of this pathway in the inhibitory action of relaxin. First, relaxin stimulates an increase in uterine cAMP concentrations only when a phosphodiesterase inhibitor is present (Sanborn et al., 1980; Hsu et al., 1985). Second, the time courses for the increase in uterine cAMP concentrations in vitro (Sanborn et al., 1980; Hsu et al., 1985) and for PKA activation (Kemp and Niall, 1981) are slower than those for mechanical inhibition. Third, a prolonged inhibition of contractions by relaxin in vivo is associated with only a short duration of raised cAMP concentrations in the uterus $e x$ vivo, and doses of relaxin and of salbutamol (an agonist at $\beta$-adrenoceptors that induces mechanical inhibition comparable with that of relaxin) induced markedly different increases of cAMP concentrations (relaxin increases it threefold while salbutamol increases it 19-fold) (Downing et al., 1992). Finally, low concentrations of relaxin have a pharmacological profile consistent with a primary site of action at the plasmalemma in the modification of ion channel activity (Hughes and Hollingsworth, 1995). Similiar inconsistencies have been identified for the cardiac stimulant actions of relaxin. Summers et al. (1994) failed to observe any changes in cAMP concentrations in the rat atria in response to relaxin, whereas Han et al. (1994) found that a protein kinase inhibitor prevented the stimulant effects of relaxin in rabbit hearts. 
Such inconsistencies may be partially explained if the changes in cAMP concentrations in any tissue are too small to be readily detected, and hence do not reflect the activation of enzymes further down the cascade of intracellular events and the end physiological effect (Corbin, 1983). Small changes in CAMP are often associated with larger changes in PKA activity (Corbin, 1983), a feature known as amplification (Kenakin, 1993), and so PKA activity may be a preferable biochemical index. PKA is present in the rat uterus, both in the endometrium and myometrium (Korenman and Krall, 1977). cAMP-PKA consists of two regulatory and two catalytic subunits (Corbin, 1983). When cAMP binds to a regulatory subunit, an active catalytic subunit is released from the holoenzyme. Hence, PKA activity is commoniy given as the PKA activity ratio, which is the amount of PKA in the active form expressed as a fraction of the total PKA in the tissue in the presence of excess added cAMP (Corbin, 1983).

Another explanation for some of the inconsistencies listed above may be that relaxin acts partly or totally indirectly via the release of a factor from the endometrium. Although some of the biochemical studies have been conducted with myometrial cells (Anwer et al., 1990; Sanborn et al., 1994), many have been carried out on the whole uterus and so may reflect in part changes in the endometrium and not the myometrium. A potential mediator is nitric oxide, which is synthesized in the rat uterus and is a relaxant of myometrium (Yallampalli et al., 1993).

The aim of this study was, therefore, to investigate the role of the adenylyl cyclase pathway in the mechanism of the relaxant action of relaxin in the isolated uterus of nonpregnant rats, and to determine whether the action was direct or indirect. These aims were achieved by determining (1) the ability of the PKA inhibitor $\mathrm{H}-8$ or $\mathrm{N}^{\omega}$ nitro l-arginine methyl ester (L-NAME), an inhibitor of nitric oxide synthase (Norman, 1996), to antagonize relaxin in tissue bath experiments, and (2) the ability of relaxin to increase the PKA activity ratio both in longitudinal myometrium and in the intact uterus (longitudinal plus circular myometrium and endometrium). The action of relaxin was compared with that of three standard relaxants: levcromakalim, a $\mathrm{K}^{+}$-channel opener the actions of which do not involve the adenylyl cyclase pathway (Piper et al., 1990; Edwards and Weston, 1994); salbutamol, a $\beta$-adrenoceptor agonist, for which there is much evidence supporting its role in the adenylyl cyclase pathway (Diamond, 1990); and nifedipine, a $\mathrm{Ca}^{2+}$-channel blocker (Granger et al., 1986).

\section{Materials and Methods}

\section{Animals}

Female, nonpregnant Sprague-Dawley rats (200-300 g) were purchased from Charles River Ltd (Margate) and housed in the Biological Services Unit at Manchester University. Rats were pretreated with oestradiol benzoate $\left(100 \mu \mathrm{g} \mathrm{kg}{ }^{-1}\right.$ in arachis oil, $1 \mathrm{ml} \mathrm{kg}^{-1}$ s.c.) $18-24 \mathrm{~h}$ before experimentation. Rats were killed and uterine horns removed and placed in a physiological salt solution (PSS).

\section{Drugs and solutions}

Levcromakalim (SmithKline Beecham, Welwyn Garden City), salbutamol sulfate (Glaxo, Stevenage), nifedipine (Bayer, Newbury), oxytocin acetate, oestradiol benzoate, EDTA, Tris$\mathrm{HCl}$, 3-isobutyl-1-methylxanthine (IBMX), kemptide, cAMP, protein kinase inhibitor (PKI) (6-22)amide (Thr6-Tyr-AlaAsp-Phe-Ile-Ala-Ser-Gly-Arg-Thr-Gly-Arg-Arg-Asn-Ala-Ile22$\mathrm{NH}_{2}$ ), L-NAME, BSA (Sigma, Poole), H-8 (Research Biochemicals Incorporated, St Albans), concentrated phosphoric acid (Aldrich, Gillingham), $\left.{ }^{32} \mathrm{P}\right]$ ATP (167 TBq $\mathrm{mmol} \mathrm{l}^{-1}$; ICN Biomedical Inc., Thame), and Ecoscint (National Diagnostics, Wigan) were used during the course of the experiments.

Porcine relaxin was isolated from pregnant sow ovaries according to the method of Sherwood and O'Byrne (1974) by S. J. Downing (Department of Biology, University of York). Relaxin was bioassayed in vitro by inhibiting the electrically stimulated uterus from rats that had been treated with $100 \mu \mathrm{g}$ oestrogen $\mathrm{kg}^{-1}$; porcine relaxin, kindly donated by $\mathrm{O}$. D. Sherwood (Department of Physiology and Biophysics, University of Illinois), was the standard. The relaxin preparation was found to be equipotent with highly purified relaxin.

Stock solutions were prepared in the following solvents: levcromakalim in $70 \%(\mathrm{v} / \mathrm{v})$ ethanol; salbutamol in $0.1 \mathrm{~mol} \mathrm{HCl}$ $1^{-1}$; relaxin in saline; oxytocin acetate, nifedipine and $\mathrm{H}-8$ in double-distilled water; oestradiol benzoate in arachis oil. Serial dilutions of stock solutions were made in saline on the day of use. The PSS had the following composition:

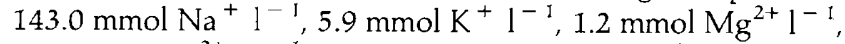
$2.6 \mathrm{mmol} \mathrm{Ca}{ }^{2+} 1^{-1}, 1.2 \mathrm{mmol} \mathrm{H}_{2} \mathrm{PO}_{4}^{-} \mathrm{l}^{-1}, 1.2 \mathrm{mmol}$ $\mathrm{SO}_{4}{ }^{2-} \mathrm{l}^{-1}, 128.0 \mathrm{mmol} \mathrm{Cl}{ }^{-1}, 25.0 \mathrm{mmol} \mathrm{HCO}_{3}{ }^{-} \mathrm{I}^{-1}$, and $11.0 \mathrm{mmol}$ glucose $\mathrm{l}^{-1}$.

\section{Tissue bath experiments}

Tissue preparation. Experiments investigating the effects of H-8 or L-NAME upon the three relaxants were performed upon tubular segments of intact uterus that were prepared for the recording of tension in the longitudinal plane. For experiments comparing the effects of the relaxants on tension development in the intact uterus and separated longitudinal myometrium, the two tubular horns of each uterus were cut along the mesometrial border, opened out and pinned to a cork board. The tissue of one horn was left intact while the endometrium and circular muscle layer were removed from the other horn using a pair of fine forceps. The tissue from each horn was cut into two equal rectangular segments and prepared for the isometric recording of tension. Tissues were mounted in $10 \mathrm{ml}$ tissue baths containing PSS at $37^{\circ} \mathrm{C}$, gassed with $95 \% \mathrm{O}_{2}$ and $5 \% \mathrm{CO}_{2}$, and allowed to equilibrate under $1 \mathrm{~g}$ tension for 30-60 min before experimentation. Mechanical responses were measured as the integral of the tension versus the time curve, as described by Granger et al. (1985).

Antagonism of the relaxants by $\mathrm{H}-8$ or by L-NAME. After equilibration in PSS, the tissues were incubated in $100 \mu \mathrm{mol}$ $\mathrm{H}-8 \mathrm{I}^{-1}$ (as described by Anwer et al., 1990) (test tissues) or vehicle (control tissues) for 20 min before adding PSS containing $0.2 \mathrm{nmol}$ oxytocin $\mathrm{1}^{-1}$ plus $\mathrm{H}-8$ or vehicle. After equilibration for $15 \mathrm{~min}$ with $0.2 \mathrm{nmol}$ oxytocin $1^{-1}$, a single, 
cumulative, concentration-effect curve was constructed for relaxin, levcromakalim or salbutamol in the continued presence of $\mathrm{H}-8$ or vehicle. The concentration of relaxin, levcromakalim or salbutamol was doubled every $10 \mathrm{~min}$ until $100 \%$ or maximal inhibition was achieved. The same experimental design was used with $10 \mu \mathrm{mol}$ L-NAME $1^{-1}$.

Effects of relaxants on oxytocin-induced phasic spasm in intact uterus and longitudinal myometrium. After equilibration in PSS, the tissues were incubated for $15 \mathrm{~min}$ in PSS containing $0.2 \mathrm{nmol}$ oxytocin $\mathrm{I}^{-1}$. One of the two segments of each intact uterus and of longitudinal myometrium was exposed to oxytocin-containing PSS but not to relaxants, to measure any decline of the spasm with time. In the other segment, a single, cumulative, concentration-effect curve was constructed for relaxin, salbutamol, nifedipine or levcromakalim.

Statistical analysis. The integrated tension recorded during the 5-10 min period after the addition of each concentration of drug is expressed as a percentage of the integrated tension recorded during the $5 \mathrm{~min}$ period before drug addition; this gives a value for the percentage spasm remaining in the presence of relaxant. $\mathrm{pD}_{2}$ values and $\log _{10}$ concentration ratios were calculated and statistical analysis was performed as described by Hughes and Hollingsworth (1995).

\section{Determination of the PKA activity ratio and the effects of relaxants}

PKA activity was monitored by measuring the incorporation of $\left[\gamma_{-}{ }^{32} \mathrm{P}\right]$ ATP into a substrate protein kemptide, which was monitored by liquid scintillation counting. The tissue extracts were assayed under four conditions: the absence and presence of cAMP and of $\mathrm{PKI}(6-22)$ amide, the purported selective inhibitor of cAMP-dependent PKA (Glass et al., 1989). This approach ensured that activity specific to this PKA was monitored.

Preparation of tissue homogenate. On each experimental day, both horns of each uterus were prepared in the same manner to give four tissue segments of either intact uterus or longitudinal myometrium. The tissues were first mounted in tissue baths to record tension changes, as described above. Tissues were exposed to PSS containing $0.2 \mathrm{nmol}$ oxytocin $1^{-1}$ for $15 \mathrm{~min}$ before exposure to a single concentration of relaxant (salbutamol, relaxin or levcromakalim) for $1 \mathrm{~min}$. In one experiment, each tissue was exposed to the same concentration of relaxin $\left(300 \mathrm{nmol} \mathrm{l^{-1 }}\right)$ but for various durations ( $1,2,4$ or $6 \mathrm{~min})$. After incubation with relaxant, the tissues were removed from the tissue baths and frozen in liquid nitrogen. Each frozen tissue was powdered and transferred to a glass test tube containing $1 \mathrm{ml}$ extraction buffer $\left(50 \mathrm{mmol}\right.$ Tris- $\mathrm{HCl} \mathrm{l^{-1 }}, 10 \mathrm{mmol}$ EDTA $\left.\mathrm{l}^{-1}\right), 0.5 \mathrm{mmol}$ IBMX $\mathrm{I}^{-1}$ and $100 \mathrm{mmol}$ sodium chloride $\mathrm{I}^{-1}$ and was stored on ice while the rest of the tissues were prepared. The tissue homogenates were centrifuged in a Mistral 6000 centrifuge at $4^{\circ} \mathrm{C}$ for $5 \mathrm{~min}$ at 6000 r.p.m. The tubes containing the pellet and the supernatant were stored on ice until required.
Assay procedure. The procedure was modified from that of the Gibco BRL (Uxbridge) Protein Kinase A Assay System and methods used by Corbin et al. (1983) and Murray et al. (1990). The assay was performed in Eppendorf tubes in duplicate. The tissue supernatants were incubated in substrate buffer $(50 \mathrm{mmol}$ Tris-HCl $1^{-1}, 40 \mathrm{mmol} \mathrm{MgCl}_{2} \mathrm{l}^{-1}, 400 \mu \mathrm{mol}$ ATP l ${ }^{-1}, 1 \mathrm{mg}$

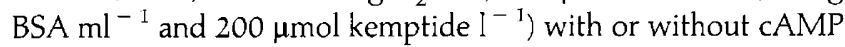
and/or PKI(6-22)amide at room temperature for $15 \mathrm{~min}$. This approach allowed the cAMP to activate the enzyme and/or PKI(6-22)amide to bind to any PKA and ensured that activity specific to cAMP-dependent PKA was measured. The tubes were transferred to an Eppendorf mixer, maintained at $30^{\circ} \mathrm{C}$, and $20 \mu \mathrm{l}$ of $\left[{ }^{32} \mathrm{P}\right] \mathrm{ATP} /$ substrate solution was added to each tube to initiate the reaction. The assay tubes each contained the following final concentrations: $50 \mathrm{mmol}$ Tris- $\mathrm{HCl} \mathrm{I}^{-1}(\mathrm{pH} 7.5)$, $10 \mathrm{mmol} \mathrm{MgCl} \mathrm{I}^{-1}, 100 \mu \mathrm{mol}\left[{ }^{32} \mathrm{PlATP} 1^{-1}(8 \mathrm{nmol}\right.$ per assay tube; $167 \mathrm{TBq}$ per $\mathrm{mmol}$ ), $0.25 \mathrm{mg} \mathrm{BSA} \mathrm{ml}^{-1}$, and $50 \mu \mathrm{mol}$ kemptide $\mathrm{l}^{-1}$, with or without $10 \mu \mathrm{mol} \mathrm{cAMP} \mathrm{I}^{-1}$ or $1 \mu \mathrm{mol}$ PKI $(6-22)$ amide $1^{-1}$. The assay tubes were incubated for $6 \mathrm{~min}$. The reaction was terminated by spotting $40 \mu \mathrm{l}$ of the $80 \mu \mathrm{l}$ of solution on to phosphocellulose paper (Whatman, Maidstone), which was washed twice with $250 \mathrm{ml}$ phosphoric acid $(1 \%, v / v)$ and a further three times with water to remove $\left[\gamma_{-}{ }^{32} \mathrm{P}\right] A$ TP. The squares of phosphocellulose were put into scintillation vials and $3 \mathrm{ml}$ Ecoscint scintillant was added. The radioactive ${ }^{32} \mathrm{P}$ label was determined by liquid scintillation counting (Packard Tricarb $460 \mathrm{C}$ Liquid Scintillation Counter). A $20 \mu \mathrm{l}$ sample of the $\left[{ }^{32} \mathrm{P}\right] \mathrm{ATP} /$ substrate solution was counted to measure the total activity added to the reaction mixture and a square of phosphocellulose, washed only with phosphoric acid and water, was counted to measure the background count.

Statistical analysis. The rationale is as described in the Gibco BRL kit. The PKA activity (nmol $\mathrm{min}^{-1} \mathrm{ml}^{-1}$ ) was calculated for each of the four conditions. The amount of activated PKA due to relaxant expressed as a proportion of the total PKA activity gave the decimal fraction of activated PKA, or PKA activity ratio. Mean activity ratios for control and drug-exposed groups were compared using the Kruskal-Wallis non-parametric test of analysis of variance, followed by MannWhitney analysis between pairs to locate differences; $P<0.05$ was taken as significant.

\section{Results}

\section{Relaxant inhibition of oxytocin-induced spasm and the effects of H-8 and L-NAME}

These experiments were performed in the intact uterus. Oxytocin induced phasic spasms that were regular in frequency and amplitude, and the integral of spasm was well maintained for the duration of the experiment (Hughes and Hollingsworth, 1995). Cumulative addition of levcromakalim $(0.025-0.8 \mu \mathrm{mol}$ $\left.1^{-1}\right)$, salbutamol $\left(0.125-8 \mu \mathrm{mol} \mathrm{l}^{-1}\right)$ or relaxin $(0.8-50 \mathrm{nmol}$ $\left.1^{-1}\right)$ produced a reversible, concentration-dependent reduction of the integral of oxytocin-induced tension waves (Fig. 1). $\mathrm{H}-8\left(100 \mu \mathrm{mol} 1^{-1}\right)$ shifted the $\log _{10}$ concentration-effect curves for salbutamol and relaxin to the right by factors of 1.9 and 3.1, respectively (Fig. 1; Table 1). In the presence of $\mathrm{H}-8$ 
(a)

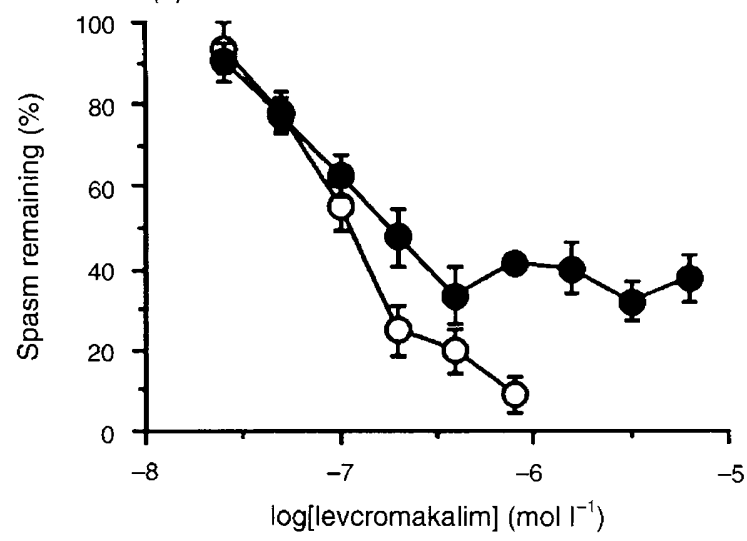

(b)

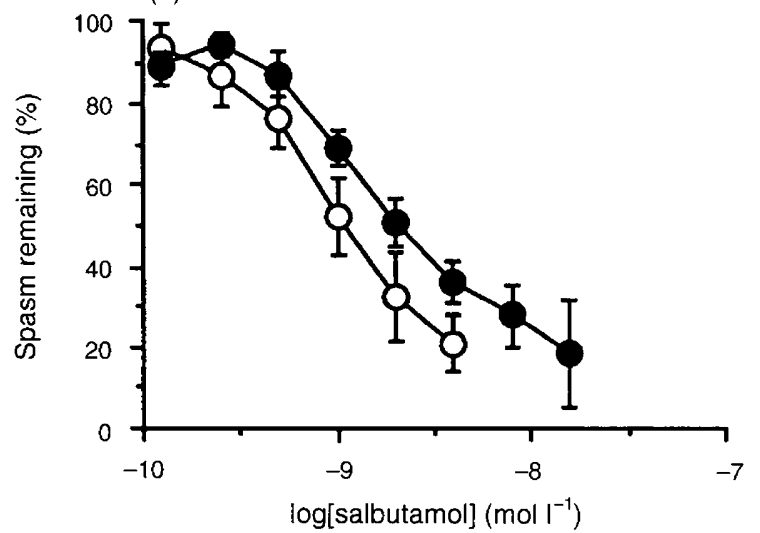

(c)

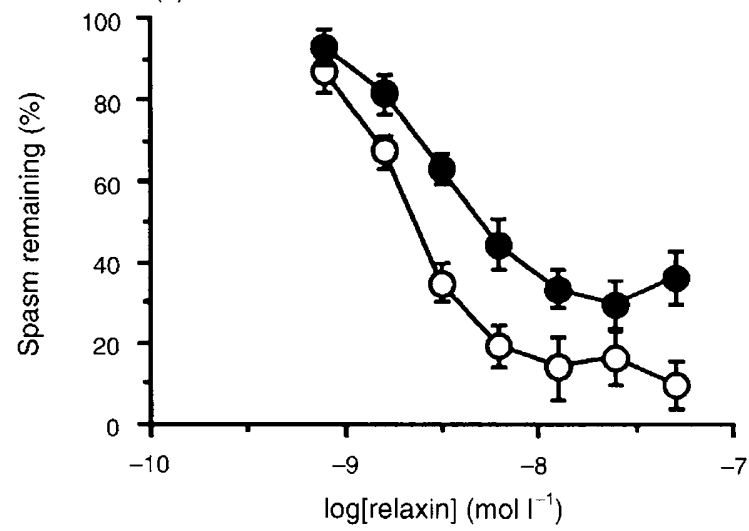

Fig. 1. The effect of $N$-[2-(methylamino)ethyl]-5-isoquinolinesulfonamide hydrochloride $\left(\mathrm{H}-8 ; 100 \mu \mathrm{mol} \mathrm{I}^{-\mathrm{I}}\right)$ on the inhibition of spasm (induced by oxytocin; $0.2 \mathrm{nmol} \mathrm{I}^{-1}$ ) evoked by (a) levcromakalim, (b) salbutamol, and (c) relaxin in intact, isolated uteri from nonpregnant rats pretreated with oestradiol. Effects are shown in the absence $(0)$ and presence $(0)$ of $\mathrm{H}-8$. The $y$ axes show the spasm remaining as a percentage of that recorded before any relaxant was added. The $x$ axes are the $\log _{10}$ concentrations of relaxant. Points represent the means and the vertical lines the SEM of six-eight tissues.

(100 $\mu \mathrm{mol} \mathrm{l}^{-1}$ ), the $\log _{10}$ concentration-effect curve for levcromakalim was shifted to the right by a factor of 2.8 . The maximal effects of levcromakalim and relaxin were reduced to only $60-70 \%$ by $\mathrm{H}-8$. There was no difference in the extent of antagonism of each of the three relaxants by $\mathrm{H}-8$ at $100 \mu \mathrm{mol}$ $\mathrm{I}^{-1}(P>0.05)$. L-NAME $\left(10 \mu \mathrm{mol} \mathrm{^{-1 }}\right)$ did not antagonize relaxin $\left(\mathrm{pD}_{2}\right.$ in the absence of $\mathrm{L}-\mathrm{NAME}=7.87 \pm 0.6, n=4$; $\mathrm{pD}_{2}$ in the presence of L-NAME $\left.=8.05 \pm 0.26, n=4 ; P>0.05\right)$.

Effects of relaxants on oxytocin-induced spasm in intact uterus and longitudinal myometrium

Salbutamol $\left(0.25-32 \mathrm{nmol}^{-1}\right)$ and nifedipine (1-128 nmol $1^{-1}$ ) completely inhibited the spasm evoked by oxytocin $\left(0.2 \mathrm{nmol} \mathrm{l}^{-1}\right)$ in both tissue preparations. There was a small reduction (by a factor of $2.6 ; P<0.05$ ) in the potency of salbutamol against oxytocin-induced spasm in the longitudinal myometrium $\left(\mathrm{pD}_{2}=8.71 \pm 0.11, n=6\right)$ compared with that measured in the intact uterus $\left(\mathrm{pD}_{2}=9.12 \pm 0.09, n=8\right.$; Fig. 2). Nifedipine was equipotent against the oxytocin-induced spasm in the intact uterus $\left(\mathrm{pD}_{2}=7.93 \pm 0.06, n=4\right)$ and longitudinal myometrium $\left(\mathrm{pD}_{2}=8.01 \pm 0.08, n=4\right.$; Fig. 2 ). Levcromakalim completely inhibited the oxytocin-induced spasm in the intact uterus with a $\mathrm{pD}_{2}$ of $6.91 \pm 0.08(n=8)$ (Fig. 2). However, despite the addition of very high concentrations $\left(50 \mu \mathrm{mol} \mathrm{l}^{-1}\right)$, levcromakalim caused only a $61 \pm 7 \%(n=13)$ inhibition in the longitudinal myometrium (Fig. 2). Complete inhibition of the oxytocin-induced spasm was achieved by relaxin in the intact uterus $\left(\mathrm{pD}_{2}=7.91 \pm 0.16, n=8\right)$ while in the longitudinal myometrium the maximum effect of relaxin was only a $58 \pm 5 \%(n=7)$ inhibition at a concentration of $2.5 \mu \mathrm{mol} 1^{-1}$ (Fig. 2).

\section{Characterization of the protein kinase $A$ assay conditions}

Preliminary experiments were performed to characterize the effects of dilution upon the reaction equilibrium and the inhibitory actions of PKI(6-22)amide on PKA activity before investigating drug actions on PKA activity.

The phosphorylation of the peptide substrate kemptide was linear with respect to the dilution of the tissue extract between dilutions of $1: 4$ and $1: 16$, and the activity ratio was unchanged for dilutions between $1: 4$ and $1: 16$ in both the control and test tissues. The PKA activity stimulated by excess

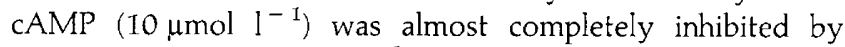
$1 \mu \mathrm{mol}$ PKI $(6-22)$ amide $1^{-1}(97.7 \pm 0.5 \%, n=6$, for a $1: 4$ dilution). Hence, a dilution of $1: 4$ was used in the rest of this study.

\section{Protein kinase $A$ assay and the effects of relaxants}

Salbutamol. The basal PKA activity ratio was slightly but significantly higher $(P<0.05)$ in tissue extracts from longitudinal myometrium than in extracts from the intact uterus (0.17 \pm 0.02 and $0.12 \pm 0.01$, respectively) (Fig. 3). The lowest concentration of salbutamol tested $\left(30 \mathrm{nmol} \mathrm{l}^{-1}\right)$ did not modify the PKA activity ratio in either tissue preparation. The PKA activity ratio was raised following incubation with the higher concentrations of salbutamol $\left(300 \mathrm{nmol} \mathrm{l}^{-1}, 3000 \mathrm{nmol}\right.$ $\left.1^{-1}\right)$ in both the intact uterus and longitudinal myometrium (Fig. 3a,b). In the presence of the highest concentration of salbutamol $\left(3000 \mathrm{nmol} \mathrm{I}^{-1}\right)$, the PKA activity ratio in the intact 
Table 1. The effect of $\mathrm{H}-8\left(100 \mu \mathrm{mol} \mathrm{l}^{-1}\right)$ on spasm induced by oxytocin $\left(0.2 \mathrm{nmol} \mathrm{l}^{-1}\right)$ in intact, isolated uteri from nonpregnant rats pretreated with oestradiol benzoate (control data are from tissues exposed to the vehicle for $\mathrm{H}-8$ and test data are from tissues exposed to $\mathrm{H}-8$ )

\begin{tabular}{lcccc}
\hline $\begin{array}{c}\text { Control } \\
\text { curve } \mathrm{pD}_{2}\end{array}$ & $\begin{array}{c}\text { Test } \\
\text { curve } \mathrm{pD}_{2}\end{array}$ & $\begin{array}{c}\log _{10} \text { concentration } \\
\text { ratio }\end{array}$ & $\begin{array}{c}\text { Concentration } \\
\text { ratio }\end{array}$ \\
\hline Levcromakalim & $6.99 \pm 0.06$ & $6.54 \pm 0.18$ & $0.45 \pm 0.19^{*}$ & 2.8 \\
Salbutamol & $8.97 \pm 0.12$ & $8.68 \pm 0.08$ & $0.29 \pm 0.14^{*}$ & 1.9 \\
Relaxin & $8.63 \pm 0.07$ & $8.14 \pm 0.12$ & $0.49 \pm 0.14^{* *}$ & 3.1 \\
\hline
\end{tabular}

Data presented are mean \pm SEM values from six-eight tissues.

${ }^{*}(P<0.05)$ and ${ }^{* *}(P<0.01)$ indicate that the $\log _{10}$ concentration ratio was significantly different from 0 .

$\mathrm{H}-8, N$-[2-(methylamino)ethyl]-5-isoquinolinesulphonamide hydrochloride.

(a)

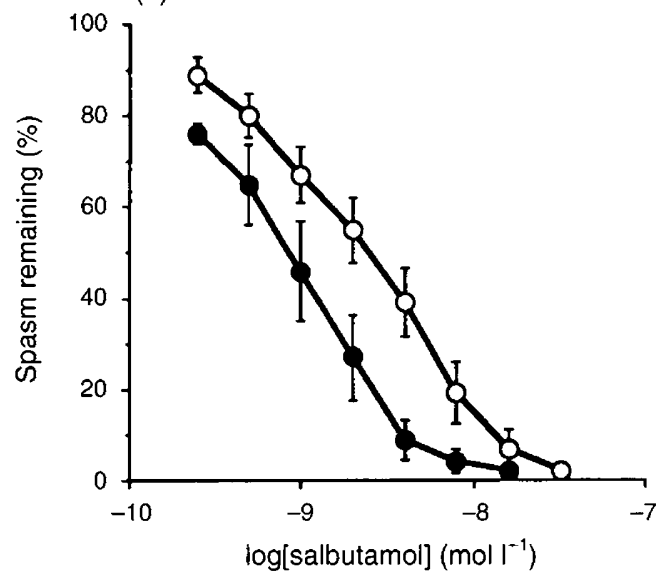

(c)

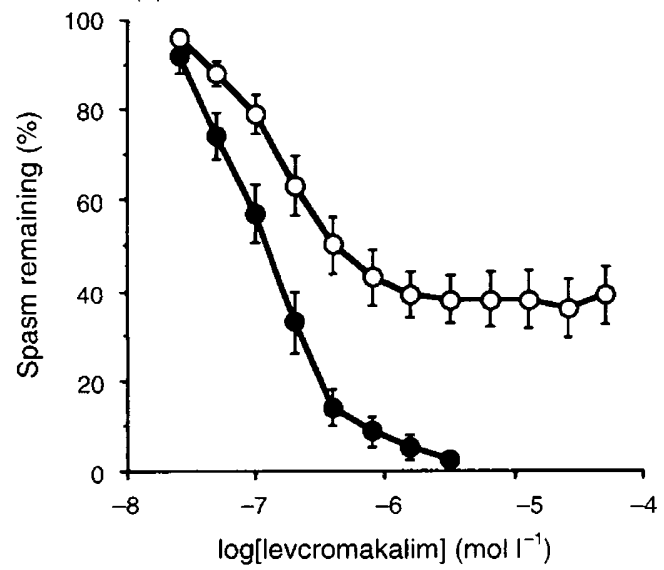

(b)

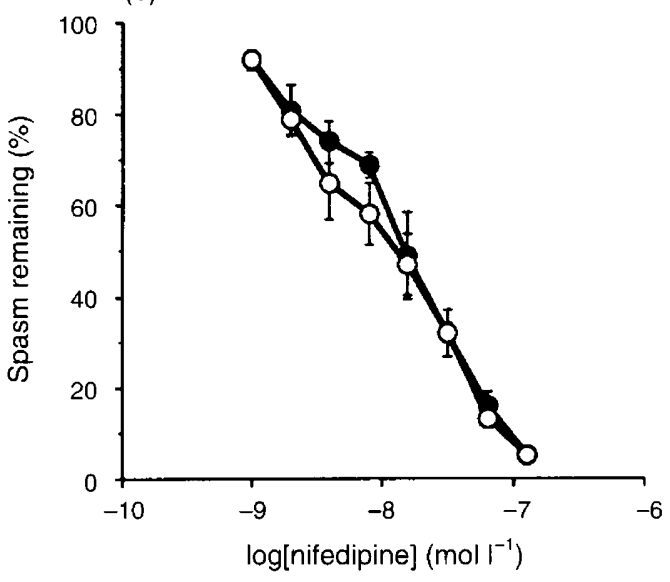

(d)

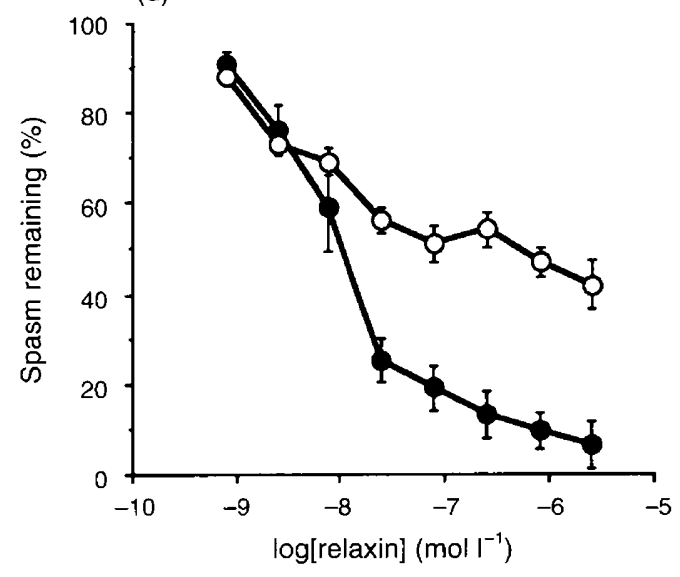

Fig. 2. Effect of (a) salbutamol, (b) nifedipine, (c) levcromakalim, and (d) relaxin on the spasm evoked by oxytocin $(0.2 \mathrm{nmol}$ $\mathrm{I}^{-1}$ ) in intact uterus $(\mathbf{O})$ and longitudinal myometrium $(O)$ from nonpregnant rats pretreated with oestradiol. The $y$ axes show the spasm remaining as a percentage of that recorded before any relaxant was added. The $x$ axes are the log 10 concentrations of relaxant. Points represent the means and the vertical lines the SEM of 4-13 tissues.

uterus was $3.8 \pm 0.3$ times the basal activity ratio, whereas the PKA activity ratio in the longitudinal myometrium was $1.9 \pm 0.3$ times the basal activity ratio.

Relaxin. The basal PKA activity ratio was again slightly but significantly higher $(P<0.05)$ in tissue extracts from longitudinal myometrium than in extracts from intact uterus
$(0.16 \pm 0.03$ and $0.11 \pm 0.02$, respectively) (Fig. 4). Relaxin did not increase the PKA activity ratio in the longitudinal myometrium (Fig. 4a). However, in the intact uterus, relaxin induced a small and significant $(P<0.05)$ rise in the PKA activity ratio at concentrations of $300 \mathrm{nmol}^{-1}(1.8 \pm 0.2$ times the basal activity ratio) and $3000 \mathrm{nmol} \mathrm{I}^{-1}(2.0 \pm 0.2$ times the basal activity ratio; Fig. 4b). 

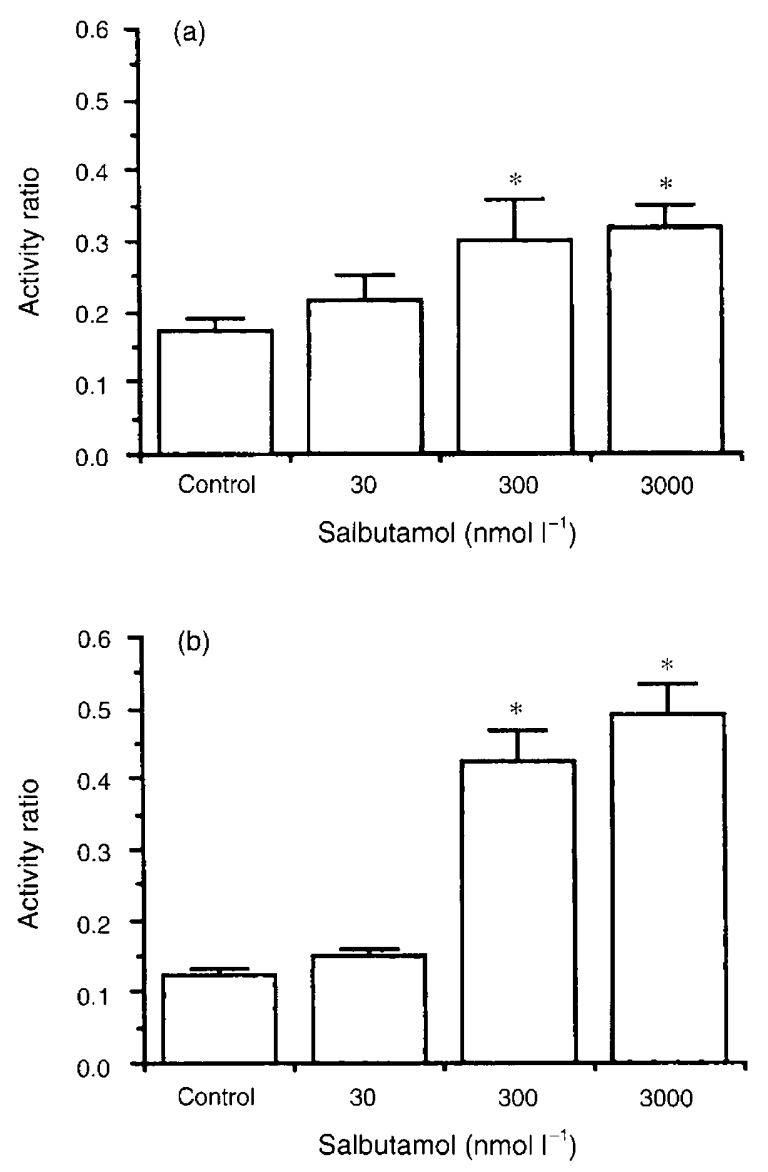

Fig. 3. The effect of salbutamol on the CAMP-dependent protein kinase $A$ activity ratio in tissue extracts from (a) longitudinal myometrium, and (b) intact uterus from nonpregnant rats pretreated with oestradiol. Bars represent the mean values and the vertical lines the SEM of four-five tissues. ${ }^{*}(P<0.05)$ indicates a value that is significantly different from the control value.

The time course of the effect of relaxin $\left(300 \mathrm{nmol} 1^{-1}\right)$ upon PKA activity in the intact uterus is shown (Fig. 5). The PKA activity ratio was maximally raised (to $1.8 \pm 0.2$ times the control value) I min after the tissue had been exposed to relaxin, and remained raised for $6 \mathrm{~min}$.

Levcromakalim. The basal value of the PKA activity ratio was measured in the intact uterus in the presence of the vehicle for levcromakalim; the concentration of the vehicle used corresponded to that applied when the highest concentration of levcromakalim $\left(100 \mu \mathrm{mol} \mathrm{^{-1 } )}\right.$ was used $(0.28 \%(\mathrm{v} / \mathrm{v})$ ethanol). This basal PKA activity ratio $(0.12 \pm 0.01)$ was not different $(P>0.05)$ from those values measured in the intact uterus on other experimental days. Levcromakalim $\left(1-100 \mu \mathrm{mol} \mathrm{l}^{-1}\right)$ did not alter the PKA activity ratio in tissue extracts prepared from segments of intact uterus (PKA activity ratio for control, $0.12 \pm 0.01$; activity ratio for $1 \mu \mathrm{mol}$ levcromakalim $\mathrm{l}^{-1}, 0.12 \pm 0.01$; for $10 \mu \mathrm{mol}^{-1}, 0.12 \pm 0.01$; and for $100 \mu \mathrm{mol} I^{-1}, 0.13 \pm 0.01$ ). The effect of levcromakalim on the PKA activity ratio in longitudinal myometrium was not assessed.
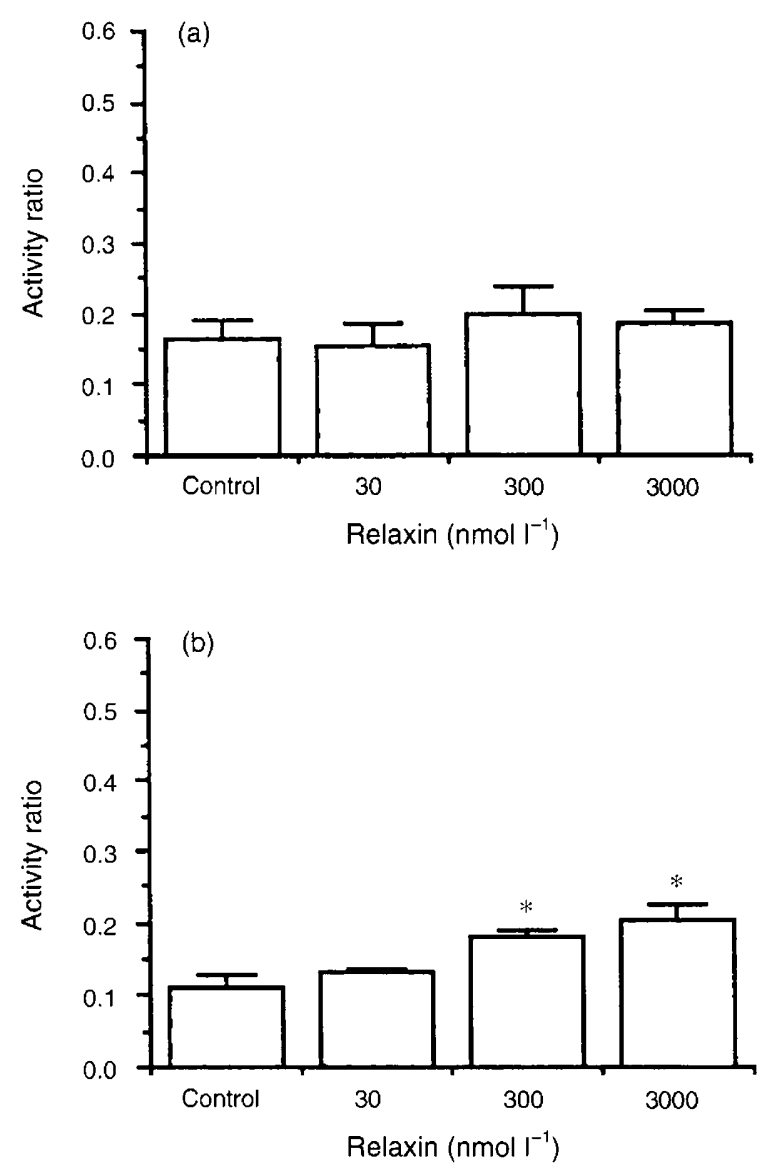

Fig. 4. The effect of relaxin on the cAMP-dependent protein kinase A activity ratio in tissue extracts from (a) longitudinal myometrium, and (b) intact uterus from nonpregnant rats pretreated with oestradiol. Bars represent the mean values and the vertical lines the SEM of five tissues. $\left.*_{\{} P<0.05\right)$ indicates a value that is significantly different from the control value.

\section{Discussion}

The observation that relaxin is antagonized by the purportedly selective PKA inhibitor $\mathrm{H}-8$ (at $100 \mu \mathrm{mol} \mathrm{l}^{-1}$ ) in isolated myometrial cells (Hidaka et al., 1984; Hagiwara et al., 1987) led Anwer et al. (1990) to conclude that PKA has a role in the inhibitory action of relaxin against oxytocin-induced increases in inositol trisphosphate formation and intracellular $\mathrm{Ca}^{2+}$ ion concentrations. In the current study, salbutamol, a drug known to activate the adenylyl cyclase pathway, was antagonized by $100 \mu \mathrm{mol} \mathrm{H}-8 \mathrm{l}^{-1}$, the same concentration used by Anwer et al. (1990) and Sanborn et al. (1994). However, the degree of antagonism was small, which perhaps reflects the lack of intracellular penetration of $\mathrm{H}-8$.

Levcromakalim was also antagonized by $\mathrm{H}-8$ and to a similar extent to salbutamol. There is substantial evidence suggesting that the opening of a $\mathrm{K}^{+}$channel is the primary mechanism of action of levcromakalim, with no involvement of adenylyl cyclase activation (Edwards and Weston, 1994). The simplest explanation for these observations is that $\mathrm{H}-8$ is not a selective inhibitor of PKA in whole tissues. Recent data suggest that H-8 can inhibit protein kinases other than cAMP-dependent 


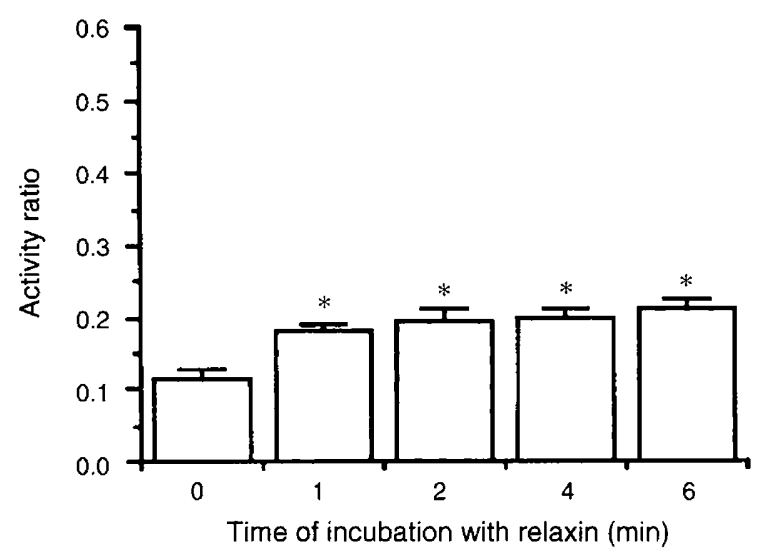

Fig. 5. Time course of the action of relaxin $\left(300 \mathrm{nmol}^{-1}\right)$ on the cAMP-dependent protein kinase A activity ratio in tissue extracts of the intact uterus from nonpregnant rats pretreated with oestradiol. Tissues were exposed to relaxin in the tissue bath for 1-6 min before the tissue extract was prepared. Bars represent the mean values and the vertical lines the SEM of four-five tissues. ${ }^{*}(P<0.05)$ indicates a value that is significantly different from the control value.

protein kinases (Fujii et al., 1995); therefore, the effects observed could be due to inhibition of these kinases in addition to PKA.

Relaxin was antagonized by $\mathrm{H}-8$ and to a similar extent to the two comparison drugs. However, in light of the antagonism of levcromakalim, the antagonism of relaxin by $\mathrm{H}-8$ cannot be taken to indicate that relaxin acts via PKA.

Control experiments demonstrated that the PKA assay could measure PKA activity in the uterus. The activity ratio was independent of dilution over the range used, showing that the holoenzyme did not dissociate during the procedure (Corbin, 1983; Murray et al., 1990). The inhibitor PKI(6-22)amide $\left(1 \mu \mathrm{mol} \mathrm{I}^{-1}\right)$ almost completely inhibited drug-induced activity, demonstrating activation and specific measurement of PKA.

It is well known that salbutamol activates the adenylyl cyclase pathway (Diamond, 1990); in this study, it acted as the positive control. In tissue bath studies, salbutamol was slightly less potent as a relaxant in the longitudinal myometrium than in the intact uterus. This observation might indicate that part of the inhibitory action of salbutamol in the intact uterus is mediated via the circular muscle layer or the endometrium. Alternatively, its reduced potency in the longitudinal myometrium may have resulted from damage inflicted to this layer when removing the circular muscle layer and the endometrium. However, the potency of nifedipine was the same in the two preparations, indicating that non-specific tissue damage probably did not occur and does not account for the reduced potency of salbutamol in the longitudinal myometrium. The PKA activity ratio was markedly increased by salbutamol in both the longitudinal myometrium and the intact uterus. Salbutamol induced a proportionally larger change in the PKA activity in the intact uterus than in the longitudinal myometrium, possibly reflecting the greater potency of salbutamol as a relaxant in the uterus.

Levcromakalim induced complete inhibition of the oxytocininduced spasm in intact uterus; however, the maximum effect was only $60 \%$ inhibition in the longitudinal myometrium and this result could be achieved only in the presence of high concentrations of levcromakalim. The maximum effect was similarly reduced in the presence of $\mathrm{H}-8$. These observations suggest that the inhibitory action of levcromakalim on the intact uterus is partly indirect and dependent upon a factor released from the circular muscle layer or the endometrium. Such observations have been observed in the rat uterus using cromakalim (Piper, 1992). Levcromakalim did not stimulate the PKA activity ratio in the intact uterus. This negative result was expected since it is well known that the major action of levcromakalim is to open $\mathrm{K}^{+}$channels (Edwards and Weston, 1994); it corresponds to observations made in other tissues in which cromakalim did not increase cAMP concentrations (Edwards et al., 1992; Small et al., 1992), and it serves to show that the PKA assay method is selective.

Relaxin produced partial inhibition of oxytocin-induced spasm in the longitudinal myometrium but did not stimulate the PKA activity ratio. Thus, the inhibitory action of relaxin in the longitudinal myometrium is unlikely to be mediated by activation of the adenylyl cyclase pathway. It was observed that salbutamol could produce relaxation in longitudinal myometrium at concentrations below those that increase PKA activity. However, relaxin, in the same ratio of biochemical to tissue bath concentrations as salbutamol, failed to increase the PKA activity ratio. Many previous reports of relaxin-induced increases in CAMP concentrations have not localized the changes to a specific layer of the uterus. Relaxin-induced increases in cAMP concentrations have been measured in cultured myometrial cells where tissue was taken from both muscle layers, longitudinal and circular (Hsu et al., 1985), or changes were measured in intact uterus (Judson et al., 1980; Grazi et al., 1988).

Given the absence of any PKA stimulation in the longitudinal myometrium with relaxin, the stimulation of PKA seen in the intact uterus must be localized to the circular muscle layer or the endometrium. Unfortunately, it is technically extremely difficult to separate the circular myometrium from the endometrium. The observation that oxytocin-induced spasm was maximally inhibited by relaxin by only $60 \%$ in the longitudinal myometrium but that complete inhibition of this spasm was induced by relaxin in the intact uterus indicates that a part of the inhibitory action of relaxin in the intact uterus is effected via the circular muscle layer or the endometrium. It is possible that relaxin stimulates a cAMP-PKA-dependent process in the circular myometrium/endometrium that results in the release of a factor that acts in turn upon the longitudinal myometrium and leads to relaxation. It might have been speculated that the inhibitory factor is nitric oxide, which has been shown to be a relaxant of the uterus in the pregnant rat (Yallampalli et al., 1993). However, relaxin was not antagonized by L-NAME, the nitric oxide synthase inhibitor, discounting $\mathrm{NO}$ as the intermediary.

In summary, the relaxant action of relaxin in the longitudinal myometrium is independent of cAMP-dependent protein kinase and presumably does not involve the adenyiyl cyclase pathway. In contrast, relaxin has an action involving the adenylyl cyclase pathway in the circular myometrium and/or the endometrium and perhaps the release of a relaxant factor. 
S. J. Hughes was supported by the Medical Research Council. The authors thank SmithKline Beecham for levcromakalim, Glaxo Wellcome for salbutamol and Bayer for nifedipine. The authors thank $\mathrm{S}$. Downing for her time and skill in isolating the porcine relaxin.

\section{References}

Anwer K, Hovington JA and Sanborn BM (1990) Involvement of protein kinase $A$ in the regulation of intracellular free calcium and phosphoinositide turnover in rat myometrium Biology of Reproduction 43 851-859

Cheah SH and Sherwood OD (1980) Target tissues for relaxin in the rat - tissue distribution of injected ${ }^{125}$ I-labeled relaxin and tissue changes in adenosine $3^{\prime}, 5^{\prime}$-monophosphate levels after in vitro relaxin incubation Endocrinology 106 1203-1209

Corbin JD (1983) Determination of the cAMP-dependent protein kinase activity ratio in intact tissues Methods in Enzymology 99 227-232

Diamond J (1990) $\beta$-adrenoceptors, cyclic AMP, and cyclic GMP in control of uterine motility. In Uterine Function pp 249-276 Eds ME Carsten and JD Miller. Plenum Press, New York

Downing SJ and Hollingsworth M (1993) Action of relaxin on uterine contractions - a review Journal of Reproduction and Fertility 99 275-282

Downing SJ, Mcllwrath A and Hollingsworth M (1992) Cyclic adenosine $3^{\prime} 5^{\prime}$ monophosphate and the relaxant action of relaxin in the rat uterus in vivo. Journal of Reproduction and Fertility 96 857-863

Edwards G and Weston AH (1994) Effect of potassium channel modulating drugs on isolated smooth muscle. In Pharmacology of Smooth Muscle. Handbook of Experimental Pharmacology, vol. 111 pp 469-53I Eds L Szerkeres and L Gy Papp. Springer-Verlag, Berlin

Edwards G, Duty S, Tresize DJ and Weston AH (1992) Effects of potassium channel modulators on the cardiovascular system. In Potassium Channel Modulators - Pharmacological, Molecular and Clinical Aspects pp 369-421 Eds AH Weston and TC Hamilton. Blackwell Scientific Publications, Oxford

Fujii M, Ide T, Wadhwa R, Tahara H, Kaul SC, Mitsui Y, Ogata T, Oishi M and Ayusawa D (1995) Inhibitors of cGMP-dependent protein kinase block senescence induced by inactivation of $\mathrm{T}$ antigen in SV40-transformed immortal human fibroblasts Oncogene 11 627-634

Glass DB, Lunquist LJ, Katz BM and Walsh DA (1989) Protein kinase inhibitor(6-22)amide peptide analogs with standard and nonstandard amino acid substitutions for phenylalanine 10 Journal of Biological Chemistry 264 14 579-14 584

Granger SE, Hollingsworth M and Weston AH (1985) A comparison of several calcium antagonists on uterine, vascular and cardiac muscles from the rat British Journal of Pharmacology 85 255-262

Granger SE, Hollingsworth M and Weston AH (1986) Effects of calcium entry blockers on tension development and calcium influx in rat uterus British journal of Pharmacology 87 147-156

Grazi RV, Goldsmith LT, Schmidt CL, Von Hagen S and Weiss G (1988) Synergistic effect of relaxin and progesterone on cyclic adenosine $3^{\prime} 5^{\prime}$ monophosphate levels in the rat uterus American Journal of Obstetrics and Gynecology 159 1402-1406

Hagiwara M, Ingaki M and Hidaka $\mathbf{H}$ (1987) Specific binding of a novel compound, $\mathrm{N}$-[2-(methylamino) ethyl]-5-isoquinolinesulfonamide $(\mathrm{H}-8)$ to the active site of CAMP-dependent protein kinase Molecular Pharmacology 31 523-528

Han X, Habuchi $Y$ and Giles WR (1994) Relaxin increases heart rate by modulating calcium current in cardiac pacemaker cells Circulation Research $\mathbf{7 4}$ 537-541

Hidaka H, Inagaki M, Kawamoto S and Sasaki Y (1984) Isoquinolinesulfonamides, novel and potent inhibitors of cyclic nucleotide dependent protein kinase and protein kinase C Biochemistry 23 5036-5041
Hsu CJ, McCormack SM and Sanborn BM (1985) The effect of relaxin on cyclic adenosine $3^{\prime} 5^{\prime}$-monophosphate concentrations in rat myometrial cells in culture Endocrinology 116 2029-2035

Hughes SJ and Hollingsworth M (1995) Cellular localization of the inhibitory action of relaxin against uterine spasm British Journal of Pharmacology 116 3028-3034

Hughes SJ and Hollingsworth M (1996) The lack of a role for potassium channel opening in the action of relaxin in the isolated rat uterus; a comparison with levcromakalim and salbutamol British Journal of Pharmacology 117 $1435-1442$

Judson DG, Pay S and Bhoola KD (1980) Modulation of cyclic AMP in isolated rat uterine tissue slices by porcine relaxin Journal of Endocrinology 87 153-159

Kemp B and Niall HD (1981) Effect of relaxin on the activation of cAMPdependent protein kinase in rat uterus. In Relaxin pp 273-275 Eds GD Bryant-Greenwood, HDS Niall and FC Greenwood. Elsevier/North Holland, New York

Kenakin T (1993) Pharmacological Analysis of Drug-Receptor Interaction (2nd Edn). Raven Press, New York

Korenman SG and Krall JF (1977) The role of cAMP in the regulation of smooth muscle cell contraction in the uterus Biology of Reproduction 16 $1-7$

Murray KJ, England PJ, Lynham JA, Mills D, Schmidt-Peiffer C and Reeves ML (1990) Use of a synthetic dodecapeptide (malantide) to measure the cyclic AMP-dependent protein kinase activity ratio in a variety of tissues Biochemical Journal 267 703-708

Norman J (1996) Nitric oxide and the myometrium Pharmacology and Therapentics 70 91-100

Osa T, Inoue H and Okabe K (1991) Effects of porcine relaxin on contractions, membrane response and cyclic AMP content in rat myometrium in comparison with the effects of isoprenaline and forskolin British Journal of Pharmacology 104 950-960

Piper IT (1992) Mechanism of Action of and Tolerance Development to $\mathrm{K}^{+}$ Channel Openers in the Isolated Uterus of the Non-pregnant Rat PhD Thesis, Manchester University

Piper IT, Minshall E, Downing SJ, Hollingsworth M and Sadraei H (1990) Effects of several potassium channel openers and glibenclamide on the uterus of the rat British Joumal of Pharmacology $101901-907$

Sanborn BM, Kuo HS, Weisbrodt NW and Sherwood OD (1980) The interaction of relaxin with the rat uterus. I. Effect on cyclic nucleotide levels and spontaneous contractile activity Endocrinology 106 1210-1215

Sanborn BM, Anwer K, Monga M, Wen Y, Singh SP, Meera P, Oberti C, Toro L and Stefani E (1994) Mechanism controlling the acute effects of relaxin on the myometrium. In Progress in Relaxin Research: 2nd International Congress on the Hormone Relaxin pp 289-297 Eds AH Maclennan, GW Tregear and G-D Bryant-Greenwood. Global Publishing Service, Singapore

Sherwood OD and O'Byrne EM (1974) Purification and characterization of porcine relaxin Archives of Biochemistry and Biophysics 160 185-196

Small RC, Berry JL, Foster RW, Green KA and Murray MA (1992) The pharmacology of potassium channel openers in airways smooth muscle: relevance to airways disease. In Potassium Channel Modulators - Pharmacological, Molecular and Clinical Aspects pp 422-461 Eds AH Weston and TC Hamilton. Blackwell Scientific Publications, Oxford

Summers RJ, Tan YY, Kakouris H and Eddie LW (1994) Cardiac actions of relaxin. In Progress in Relaxin Research: 2nd International Congress on the Hormone Relaxin pp 487-498 Eds AH Maclennan, GW Tregear and G-D Bryant-Greenwood. Global Publishing Service, Singapore

Yallampalli C, Izumi H, Byam-Smith M and Garfield RE (1993) An L-argininenitric oxide-cGMP system exists in the uterus and inhibits contractility during pregnancy American Journal of Obstetrics and Gynecology 170 $175-185$ 